\title{
Should we use albumin or saline for fluid resuscitation of critically ill patients?
}

Finfer S, Bellomo R, Boyce N, French J, Myburgh J, Norton R; SAFE (Saline versus Albumin Fluid Evaluation) Study Investigators. A comparison of albumin and saline for fluid resuscitation in the intensive care unit. N Engl J Med 2004;350:2247-56.

Background: It is uncertain whether the choice of resuscitation fluid affects the survival of critically ill patients. Metaanalyses of clinical trials using colloid (albumin) administration have delivered conflicting results. ${ }^{1,2}$

Design: This prospective, multicentre, double-blind controlled trial randomly allocated critically ill adults who required intravascular fluid resuscitation to receive either $4 \%$ albumin or normal saline. The duration of intervention was 28 days from the time of admission to the intensive care unit. Other therapies and maintenance fluids were administered at the discretion of the treating clinician. Patients with severe burns or those who had undergone cardiac or liver transplantation were excluded from the study. The primary outcome measure was the all-cause 28-day mortality; secondary outcome measures included duration of survival, occurrence of organ failure, and the durations of mechanical ventilation, renal replacement therapy, intensive care and hospital stay.

Results: Of the 6997 patients who were enrolled in the study, 3497 received albumin and 3500 saline. Both groups had similar baseline demographic and clinical characteristics. During the first 4 days after admission, patients in the albumin group required nearly $30 \%$ less volume of the study fluid than did those assigned to receive saline. Central venous pressure and serum albumin levels were significantly greater in the albumin group. However, the mean arterial pressure did not differ significantly between the 2 groups, nor did the primary and secondary outcome measures. The study outcomes are summarized in Table 1.

Commentary: The SAFE study is a landmark trial. It is the largest and most carefully designed and executed trial of albumin use for fluid resuscitation of critically ill patients. The findings are clear: the use of albumin or saline results in similar clinical outcomes at 28 days. It is important to note that the analyses of deaths from various causes were not predefined; the results therefore should be interpreted with caution.

Although albumin appears to be safe, its lack of incremental efficacy and its significantly in- creased cost provide compelling reasons against its routine use for fluid resuscitation of most critically ill patients. There remain interesting and important questions: Are there true differential effects in the subgroups of patients with traumatic injuries or sepsis? Would 25\% albumin or albumin in combination with diuretics influence outcomes? Would other colloids (e.g., gelatins or starches) have distinct roles and benefits in fluid resuscitation? For now, answers to these questions should be guided by sound physiology and available evidence, while we await further results from highquality investigations such as the SAFE study.

\section{Roy Ilan \\ Department of Critical Care Medicine}

Robert A. Fowler

Division of General Internal Medicine and Interdepartmental Division of Critical Care Medicine Sunnybrook and Women's College Health Sciences Centre

Toronto, Ont.

\section{References}

1. Cochrane Injuries Group Albumin Reviewers. Human albumin administration in critically ill patients: systematic review of randomized controlled trials. BM7 1998;317:235-40.

2. Wilkes MM, Navickis RJ. Patient survival after human albumin administration: a meta-analysis of randomized controlled trials. Ann Intern Med 2001;135:149-64.

\begin{tabular}{|c|c|c|c|}
\hline Outcome & Albumin & Saline & Value \\
\hline Duration of outcome, mean (SD), d & & & Absolute difference $(95 \% \mathrm{Cl})$ \\
\hline Mechanical ventilation & $4.5 \quad(6.1)$ & $4.3 \quad(5.7)$ & $0.19(-0.08$ to 0.47$)$ \\
\hline Renal replacement therapy & $0.5 \quad(2.3)$ & $0.4 \quad(2.0)$ & 0.09 (-0.0 to 0.19$)$ \\
\hline Stay in ICU & $6.5(6.6)$ & $6.2(6.2)$ & $0.24(-0.06$ to 0.54$)$ \\
\hline Hospital stay & $15.3 \quad(9.6)$ & $15.6 \quad(9.6)$ & $-0.24(-0.70$ to 0.21$)$ \\
\hline No new organ failure, number (\%) & $1397(52.7)$ & $1424(53.3)$ & $p=0.85$ \\
\hline & & & Relative risk $(95 \% \mathrm{Cl})$ \\
\hline All deaths within 28 days, no. (\%) & 726/3473 (20.9) & $729 / 3460(21.1)$ & 0.99 (0.91 to 1.09$)$ \\
\hline Trauma & $81 / 596(13.6)$ & $59 / 590 \quad(10.0)$ & 1.36 (0.99 to 1.86$)$ \\
\hline Trauma with brain injury & $59 / 241 \quad(24.5)$ & $38 / 251 \quad(15.1)$ & 1.62 (1.12 to 2.34$)$ \\
\hline Severe sepsis & 185/603 (30.7) & 217/615 (35.3) & $0.87(0.74$ to 1.02$)$ \\
\hline Acute respiratory distress syndrome & $24 / 61 \quad(39.3)$ & $28 / 66 \quad(42.4)$ & $0.93(0.61$ to 1.41$)$ \\
\hline
\end{tabular}

